\title{
MARFILES COPTOS EN VALDETORRES DE JARAMA (MADRID)
}

\author{
POR
}

\author{
MARTA CARRASCO Y MIGUEL ÁNGEL ELVIRA \\ Universidad Complutense de Madrid
}

\section{RESUMEN}

Presentación de un conjunto de marfiles tallados procedentes de la villa de Valdetorres de Jarama (provincia de Madrid). Resultan ser todos ellos piezas de importación procedentes de Egipto, y fechables entre fines del siglo iv y la primera mitad del v d.C.

Con ellos, pueden reconstruirse hipotéticamente cofres o paneles decorativos.

\section{SUMMARY}

Presentation of a series of carved ivory coming from the villa de Valdetorres de Jarama, Madrid. All of them seemed to be imported pieces coming from Egypt, and could be dated between the late fourth century and the first half of the fifth century a.C.

We could theoretically reconstruct chests or decorative panels with them.

El gran edificio octogonal de Valdetorres de Jarama (Madrid), que en su día fuera excavado por $\mathrm{L}$. Caballero, J. Arce y M. A. Elvira, sigue ofreciendo, durante el estudio de sus distintos materiales, ciertas sorpresas de interés. En concreto, quienes, con vistas a la publicación definitiva de los hallazgos, acabamos de trabajar sobre los fragmentos de marfil y hueso tallado que alli aparecieron, creemos que las conclusiones a las que ha llegado nuestra investigación merecen ser adelantadas en este articulo.

Ya por su número - que sobrepasa los cuatrocientos-, los fragmentos de marfil tallado $-\mathrm{y}$, secundariamente, de hueso- representan un conjunto más que respetable para un yacimiento de nuestra península, y, desde luego, el mayor entre los publicados del periodo tardoimperial: no cabe duda de que el propietario del edificio, aun antes de decorar los suelos - tarea que no llegó a realizar-, se lanzó a una actividad decorativa desbordante, $y$, no contento con adornar su patio, peristilo y habitaciones con un ciclo de estatuas marmóreas ya antiguas ', enriqueció algún ambiente con muebles o cofres de ricas maderas, cubiertos de taraceas de hueso y marfil.

Porque, en efecto, uno de los primeros aspectos que cabe resaltar en el conjunto que nos ocupa, y que no deja de resultar asombroso en el contexto de cualquier villa o casa romana, es que la inmensa mayor parte de los restos recogidos corresponde a placas de adorno, destinadas a enriquecer tableros de madera: sólo cinco piezas aisladas - una tablilla para escribir, una cuenta de collar, un fragmento de brazalete o pulsera, una ficha de juego con la cifra romana $\mathrm{V}$ inscrita en el centro, $\mathrm{y}$ un gozne de puerta (o acaso un mango de herramienta)-cuatro de ellas de marfil y la última de hueso, escapan a esta caracterización, y la única que reviste cierto interés es la tablilla ${ }^{2}$ : sobre su pulida superficie, muestra una serie

\footnotetext{
' Hasta la publicación de la memoria definitiva de las excavaciones, véanse las siguientes noticias y estudios sobre las esculturas y sobre la villa de Valdetorres en general: J. Arce, L. Caballero y M. A. Elvira, Valdetorres de Jarama. Informe preliminar, Madrid, 1979; de los mismos, "El octógono de Valdetorres de Jarama (Madrid)", Historia 16, 124, VIII-1986, p. 103109; C. Garralón, «La "Villa Romana" de Valdetorres del Jarama», Cuaderno de Cultura, 7, XII-1978, p. 54-55; R. Leira, "Valdetorres de Jarama: mensaje de agua", Cisneros, 75, 1-1979, p.2426; E. Baquedano, "Excavaciones en Valdetorres del Jarama», Revista de Arqueologia, 22, 1982, p.56-63; M. A. Elvira y C. Puerta, «El conjunto escultórico de Valdetorres de Jarama», Goya. 208, I y 11-1989, p. 194-199; F. Mingarro Martin et alii, "Petrologia arqueológica de esculturas procedentes de la villa romana de Valdetorres de Jarama (Madrid)", Revista de materiales y procesos geológicos, V, 1987, p. 45-70.

2 Véase fotografia en el Informe preliminar... citado en la nota anterior, p. 30 , figs. 1-2. Son ya bastantes las tablillas de este tipo publicadas. Véase, por ejemplo, la tablilla con su marco hallada en Tolsum (Holanda), en T. Bechert, Pax Romana,
} 


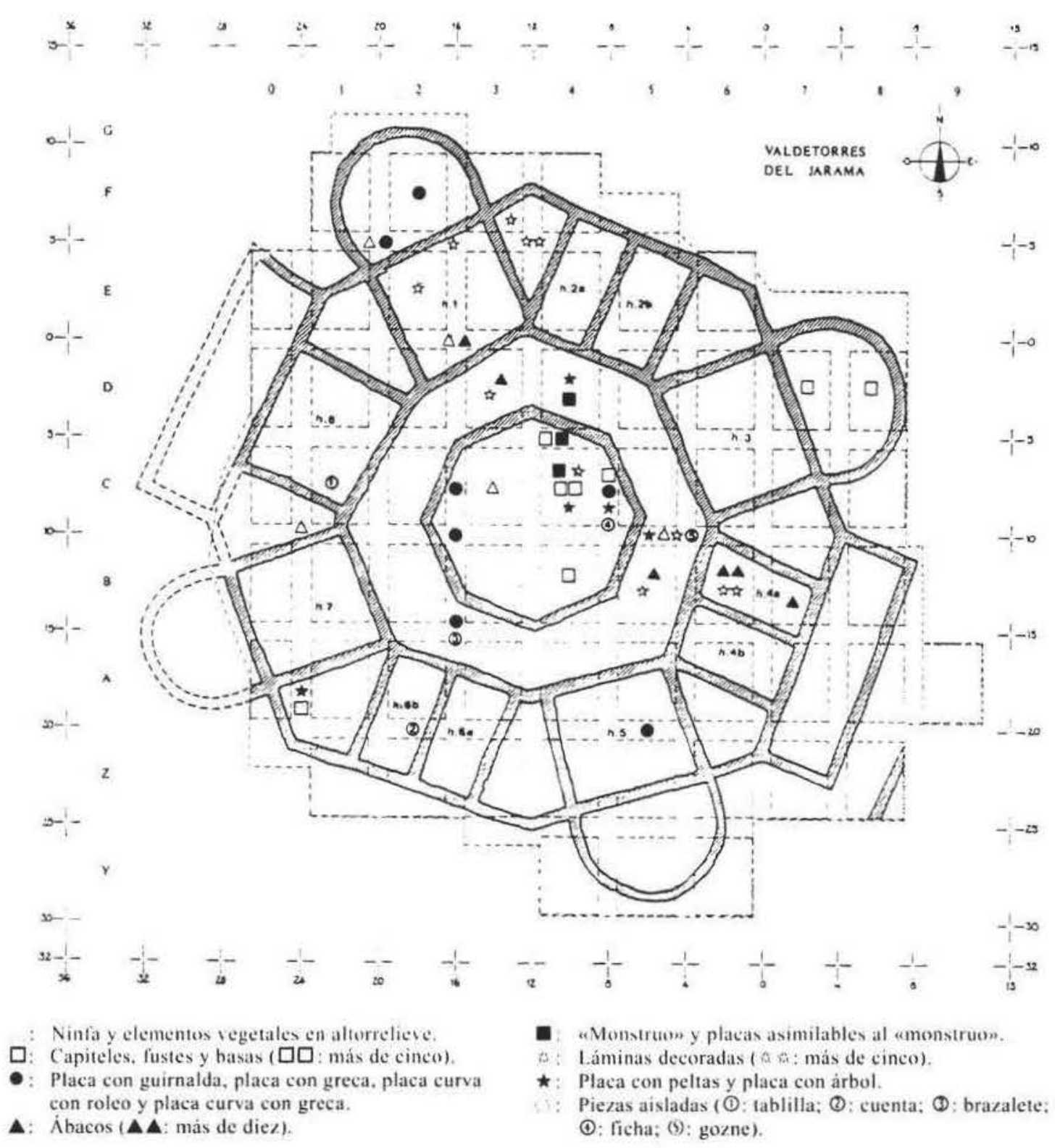

Figura 1.-Plano de distribución de los marfiles y huesos tallados de Valdetorres.

de nueve estrias longitudinales paralelas y más o menos equidistantes, que servirian para indicar las lineas por debajo del recubrimiento de cera transparente. En los lados cortos aparecen sendos escalo-

Duisburg. 1982, p. 19. También con marco, pero sin el estriado tan claro y con restos de escritura, hay otra en Rumania: Römer in Rumänien (Ausstellung des Römisch-(iermanischen Museums Köln), Colonia, 1969, lảm. 26-27. También es muy interesante la docena de tablillas descubiertas en un déposito de Vindolanda (A. K. Bowman, The Roman Writing Tahlets from Vindolanda, Londres, 1983, p. 19, fig. 9): en ellas han quedado huellas de letras grabadas en la madera porque el punzón traspasó la cera. nes rehundidos, destinados con seguridad a fijar el marco, del que no nos ha llegado resto alguno.

Las numerosas placas de taracea, $\mathrm{y}$ las láminas de recubrimiento con o sin decoración, aparecieron distribuidas en el yacimiento tal y como se muestra en el plano adjunto. Al localizarse su inmensa mayor parte en niveles de destrucción y en el inmediato sobre el suelo, siendo raras las halladas en niveles superficiales, podemos dar por cierto que ese plano de distribución corresponde al que quedó fijado en el momento - o periodo- en que el edificio se vino abajo.

Si analizamos el plano (fig.1), y añadimos los 
datos importantes de que parte de los fragmentos han aparecido quemados y que, como vamos a ver. lo llegado hasta nosotros no son sino tristes restos, por ningún concepto más de una quinta o cuarta parte de lo que fue el total de las piezas primitivas, parecen poderse extraer ciertas conclusiones. La primera es que el o los objetos decorados -inmediatamente volveremos sobre este punto- fueron conscientemente destruidos: numerosas piezas, cuyos fragmentos se han podido reunir en ocasiones, muestran roturas astilladas producidas de forma violenta, y sus restos han aparecido en ocasiones esparcidos por lugares distantes. Por tanto, no puede hablarse propiamente de un saqueo con finalidad lucrativa: si acaso, alguien pudo llevarse objetos utilitarios - como hemos visto, entre las piezas exentas faltan algunas tan comunes como los alfileres de cabello, los peines, el instrumental médico, etc...... pero se prefirió romper las más ostentosas piezas, y no robarlas.

Por lo que parece, las astillas o tablas rotas, con sus decoraciones de marfil y hueso, fueron transportadas, pero no arrojadas en cualquier dirección. Acaso se intentó usarlas como combustible, y fue, efectivamente, en el patio central donde muchas sirvieron para alimentar alguna hoguera $u$ horno.

Paralelamente, o en un momento inmediatamente posterior, cuando el edificio ya se iba hundiendo, pudo seguir la quema de maderas, y, a la vez, ocasionales visitantes del monumento en ruinas fueron recogiendo fragmentos que les atrajeron por su iconografia o belleza. Se llevaron muchos, y abandonaron otros, a veces a varios metros de donde los habian encontrado. Creemos que asi puede explicarse que sean precisamente algunas de las piezas más vistosas las que han aparecido lejos de la gran agrupación, en forma de franja alargada, que reúne los restos principales entre la habitación 1 y la $4 a$, pasando por la zona N.E. del peristilo y por el patio.

¿Cuándo se dio la destrucción consciente de las piezas, y cuántas se destruyeron? $\mathrm{He}$ ahi dos preguntas que resultan muy dificiles de contestar de forma concreta. Por lo que se refiere a la primera, sin duda será el estudio de otros materiales más susceptibles de seriación, como las cerámicas, el que dé la última palabra a la hora de fechar la destrucción de las obras de arte - incluidas las esculturas de mármol-, que iría aparejada al abandono del edificio, $\mathrm{y}$ al hundimiento de sus techos y muros. $\mathrm{A}$ título indicativo, quizá no sería aventurado pensar en una fecha a mediados del siglo $v$ para la actividad iconoclasta.

En cuanto al número de las obras, creemos - a pesar de que la distribución unitaria de los restos pudiera sugerir lo contrario - que es imposible pensar en un objeto único: la diferencia de estilos, la enorme variedad de tamaños entre algunos elementos, y hasta las grandes diferencias técnicas que pueden apreciarse - desde láminas grabadas hasta una figura en altisimo relieve, casi exenta - nos imponen una solución plural: tres o cuatro muebles o efectos varios constituirian un mínimo aceptable. En cuanto al hecho de que, en la destrucción general, sus astillas acabasen mezclándose, podria explicarse muy bien si pensásemos que las piezas adornaban una única habitación, acaso la $4 \mathrm{a}$.

Mas pasemos ya a los hallazgos en si. Como acabamos de decir, razones técnicas y estilísticas imponen suponer la existencia de tres enseres como minimo. Los fragmentos en nuestra opinión excluyentes serian:

1) Una serie de láminas con decoración grabada, de un tipo bien documentado y preciso; 2) una escultura - casi exenta, como acabamos de decirde una ninfa que vierte agua de una ánfora, y 3) la placa que denominamos «monstruo de Valdetorres», de estilo totalmente peculiar.

Antes de pasar a esas piezas, sin duda las esenciales del conjunto, comentaremos brevemente las demás, muchas de las cuales pudieron formar parte de la misma decoración que una de las tres citadas, o corresponder a otro objeto distinto y dificil de definir.

Asi, cabe comenzar señalando que la fortuna de la excavación nos permitió, en la habitación 4a, la recogida de toda una serie de láminas y placas de marfil perfectamente colocadas tal y como lo estuvieron al revestir una tabla de madera $y$, en concreto, la parte alta de un panel lateral, con su arista superior. Gracias a este hallazgo, que pudo ser perfectamente restaurado en el Museo Arqueológico Nacional de Madrid - donde hoy se hallan todos los objetos de Valdetorres-, sabemos que hubo un objeto - mueble o cofre-que presentaba, en la tabla superior y junto a la arista, una lámina plana $(0,1$ $\mathrm{cm}$. de grueso), y que, en la parte alta de su pared lateral, superponia los siguientes elementos longitudinales: una moldura de marco ondulada, una moldura de contario, un friso de dentículos o dentellones, y una superficie de láminas finas (de 0,05 $\mathrm{cm}$. de grueso), ésta de anchura indefinible.

Por desgracia, es imposible determinar si esta tabla de cierta amplitud (la parte restaurada mide $25 \mathrm{~cm}$. de largo por $6 \mathrm{~cm}$. de alto) podría conjuntarse con alguna de las tres piezas antes mencionadas, o si debe suponerse su adscripción a otro cofre o mueble distinto. Y lo mismo ocurre con los numerosos 
restos de laminas in decorar, molduras de marco de dos modelos diversos. molduras de contario y frises de denticulos a menudo con medidas bastante distuntas de pieza a pieza - que han aparecido en varios lugares de forma inconexa. Si anadimos otro tanto de numerosos fragmentos de placas de marfil a vecescon sencillisimos marcos en forma de surco o de las escasas piezas de hueso placas cuadrangulares, y una triangular elenco de los objetos de particular interes se nos reduce notablemente.

Entre ellos. merece destacarse la presencia de dos piezas cuya relación con cualquiera de las tres fundamentales y excluyentes es dudosa, pero no imposible. Una de ellas es un fragmento de placa de talla muy fina, que representa, casi completo, un pequeno arbol con tres ramas y numerosas hojas lanceoladas (fig. 2). Su estilo suave, con tronco y ramas flexibles y casi verticales, resulta tipico del Bajo Imperio, pudiendosele aducir numerosos pa-

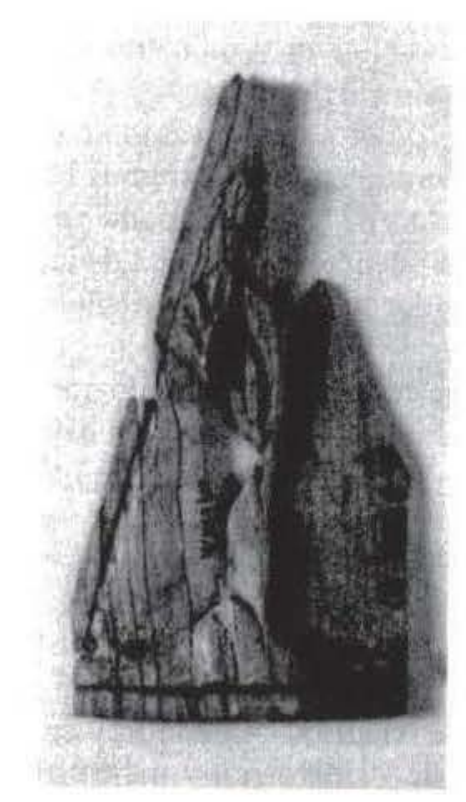

Figura 2. Placa con arbol de tres ramas.

\footnotetext{
'En particular, recuérdense los múltiples àrboles tigurados en la Lipsanoteca de Brescia (W. F. Volbach. Flfenarbeiten der Spătantike und des frähen Mittelalters ( $3^{*}$ ed ).Maguncia. 1976. n"107: G. Bovini y L. Bona Ottolenghi, Catalogo della mostra degli avori dell allo medio evo, Faenza, 1956, n"9; R. Delbrueck. Probleme der Lipsanothek in Brescia, Bonn, 1952, passim), o la placa con el Bautismo de Cristo del Museo Victoria y Alberto de Londres (W. F Volbach, op. cit, $\mathrm{n}^{\circ} 118$ ), o la pixide con milagros de Cristo de Bolonia (G. Bovini y L. Bona Ottolenghi. op. cit . $\left.\mathrm{n}^{\circ} 34\right)$, o la placa de Apolo y Dafne del museo de Rávena (W. F. Volbach, op. cit., $\mathrm{n}^{\mathrm{a}}$ 80: G. Bovini y L. Bona Ottolenghi, op cit., $\mathrm{n}^{\circ}$ 45: J. Beckwith. Coptic Sculpture, 300-1300. Londres, 1963, fig. 30).
}

ralefos pero acaso mas interesante aun es que esta placat conserve en parte los limites i/quierdoc infierior con un marco rehundido para encajar mejor otras piezas - y que estos lados formen un angulo agudo, de unos 72": nos hallamos sin dudia ante una pieza que sirvio para la tapadera de un cofre del tipo mas usado en la Antiguicdad Tardia el de tapa troncopiramidal. Es posible que esta tapadera fuese la del cofrecillocon laminas grabadas, como después veremos.

La otra pieza o más bien pieza y media. pues hay un fragmento de otra realizada con el mismo patron es una placa recortada de aspecto cuadrangular $(7.7 \times 7.7 \times 0.2)$ con una decoracion que podemos definir como de cuatro peltas enfrentadas por sus lados convexos y con flores de tres petalos surgiendo de los ángulos. Lo interesante de esas piezas de marfil es que conocemos paralelos casi identi$\cos$, aunque de forma algo más compleja. procedentes del Egipto copto ${ }^{4}$, y que podemos asegurar que se encajaban en paneles de madera formando filas. Esos paneles pudieron componer una obra independiente por ejemplo. las puertecillas de algún armario-, o bien completar la decoración presidida por la ninfa, por ejemplo.

Con esto, y dejando de lado algunas piececillas menores con motivos probablemente figurativos, pero imposibles de definir. podemos pasar ya a los tres conjuntos por completo independientes.

Constituirian el primero, como antes hemos señalado, las láminas con decoración grabada. A primera vista, su carácter fragmentario las podria hacer pasar inadvertidas, pero el diseño de sus dibujos denota gran seguridad de trazo, y. lo que es mas importante, las dos mejor conservadas - un friso curvo con una decoración de guirnalda o sogueado, y un fragmento de fuste de columna con estrias sesgadas, dejando unos sectores a un nivel más bajo (dentro de lo posible en unas láminas que tienen un grosor de $0,05 \mathrm{~cm}$.) - nos encaminan a un tipo de productos bien estudiado y atribuido unánimemente a talleres egipcios ': se trata de obras en hueso o marfil - las nuestras, casi con seguridad de marfil-donde los surcos grabados y las zonas rehundidas se rellenaban con ceras de colores negro, rojo, azul, verde - para dar un aspecto animado a las superficies. Es tipica la realización, con esta técnica. de unas "arquetas de bodas" donde aparecen figuras humanas encuadradas por columnas y arquerias

\footnotetext{
'M. H. Rutschowscaya, Catalogue des bois de l'Egyptecop. te, Musce du Louvre, Paris, 1986, p. 148, $\mathrm{n}^{\circ} 518$.

"Véase, ultimamente, el estudio de M. Albertoni, "L astrine di rivestimento dell'antica via di Porta San Lorenzon, Bull. Comm. Arch. Com di Roma, XCIX, 1991-1992, p. 341-392.
} 
comolas nuestras". Ya hemos dicho que es posible pensar en la platea con el arbol como parte de la tapadera de esta arqueta: en efecto. se sabe por las piezas mejor conservadas, que a veees alternaban pancles en bajorrelieve con las laminas grabadas y enceradas, y estos pancles tienen un estilo de carácter clasicista, aunque, normalmente. de calidad in ferior a la de nuestra placa

Pero las "arquetas de bodas" conocidas miden. todas ellas, unos $40 \mathrm{~cm}$. de altura, y nosotros tenemos en los dos brazos de una ninfa lo único que de ella se conserva - los restos de una estatua que. de estar completa, alcanzaria los $47 \mathrm{~cm}$. de alto (fig. 3). Por tanto, hemos de ver en esta figura, en altisimo relieve. con detalles exentos incluso, el resto más evocador de una pieza diferente. La ninfa pasaba su brazo derecho por encima de la cabeza, cogiendo por el pie una ánfora cuya boca sostenia, más abajo, con los delicados dedos de su mano izquierda. Sc trata de una postura bastante normal en la iconografia de estas deidades * y lo que mas asombra es la

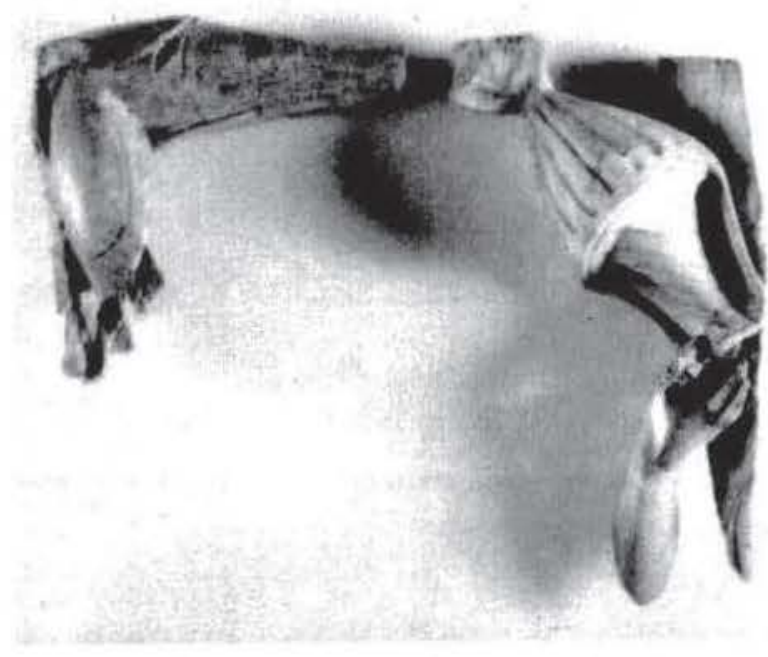

Figura 3. Restos de figura de manta en alforrelieve

\footnotetext{
"Véase op, cit. en nota anterior y, sobre todo, el cofrecillo conservado en el Museo Copto del Cairo (K. Weitzmann (ed.). Age of Spirituality, Nueva York, 1979, p. 332, n³11: o H. Buschhausen. Die spätrömische Metallscrinia und friahchristliche Reliquiare. Viena, 1971, tam. 30-31, n* B9).

Véase, en general, M. Albertoni, op. cit. en nota 5. Muy caracteristico es el caso de la arqueta de Baltimore (fig. 43 de dicho articulo; o bien Early Christian and Byzantine Art: an Exhibition held at the Baltimore Museum of Art, Battimore, 1947. $\left.n^{*} \mid 81\right)$.

"Véase, por ejemplo la decoración de una alanx» de terracota del norte de Africa, hoy en el Museo del Cairo (K. Weitzmann (ed), op. cit, en nota 6, p. 166, n" 144, o E.A. Atlante dells forme ceramic he, I, Roma, 1981, $\lim$ LXXIX, $\mathrm{n}^{\circ} 6$ ), y la de una vasija de plata del Ermitage (L. Matzulewitsch, Byzantinische Antike, Berlin/Leipzig. 1929, p. 135, fig. 47). Ambas son obras de h. 400 d.C.
}

refinadismat falla clasicista de las partes consersadas. semejante. s no superior. a las mejores piezas de cste lipo, como la Ariadna del Museo de Clunyo la serie de dioses reempleada en el pulpito de Enrique Il en la catedra! de Aquisgrion

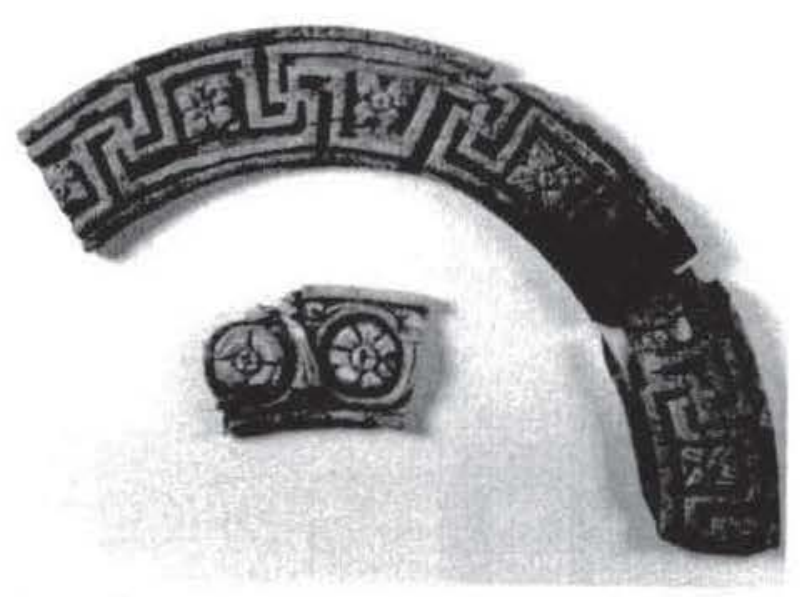

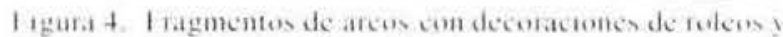
de esvasticas

Dado el tamaño y el estilo de nuestra figura, es probable - aunque hipotético - que formasen parte de la misma decoración que ella las más refinadas tallas que han aparecido en Valdetorres: fragmentos de dos arcos, uno con roleos y otro con un friso de esvásticas y florones (fig. 4), una placa recta con florones entre una greca de ménsulas, otra placa recta - hoy bastante deteriorada, pero de brillante realización, con una roseta central encuadrada por una compleja guirnalda de hojas y bayas (fig. 5). varios restos de basas de columnas - con la tipica composición de escocia entre dos toros propia de la tradición ática. unas láminas de sección en arco de circulo, con estrias, que sin duda se pegaron a tablillas de madera para dar la sensación de fustes de columna en altorrelieve, dos capiteles corintios simplificados - de los cuales el único completo muestra talladas tres caras y lisa la trasera- - y. posiblemente, algunas de las múltiples molduras con aspecto de ábaco que nos ha proporcionado la excavación.

Con todos estos elementos, y con pequeños restos de motivos vegetales que acaso completaron la figura de la Ninfa, se hubieron de construir varios

"Para la Ariadna del Museo de Cluny, que mide $40 \mathrm{~cm}$. de altura, vèase K. Weitzmann (ed.). op. cit. en nota 6. p. 148-149. $n^{\circ} 127,0$ W. F. Volbach, op ril en nota $3, n^{\circ} 78$. Para las piezas de Aquisgrán, véanse W. F. Volbach, op. cit., n' 72 ss, o J. Beckwith, op cit, en nota 3, fig. 101. 

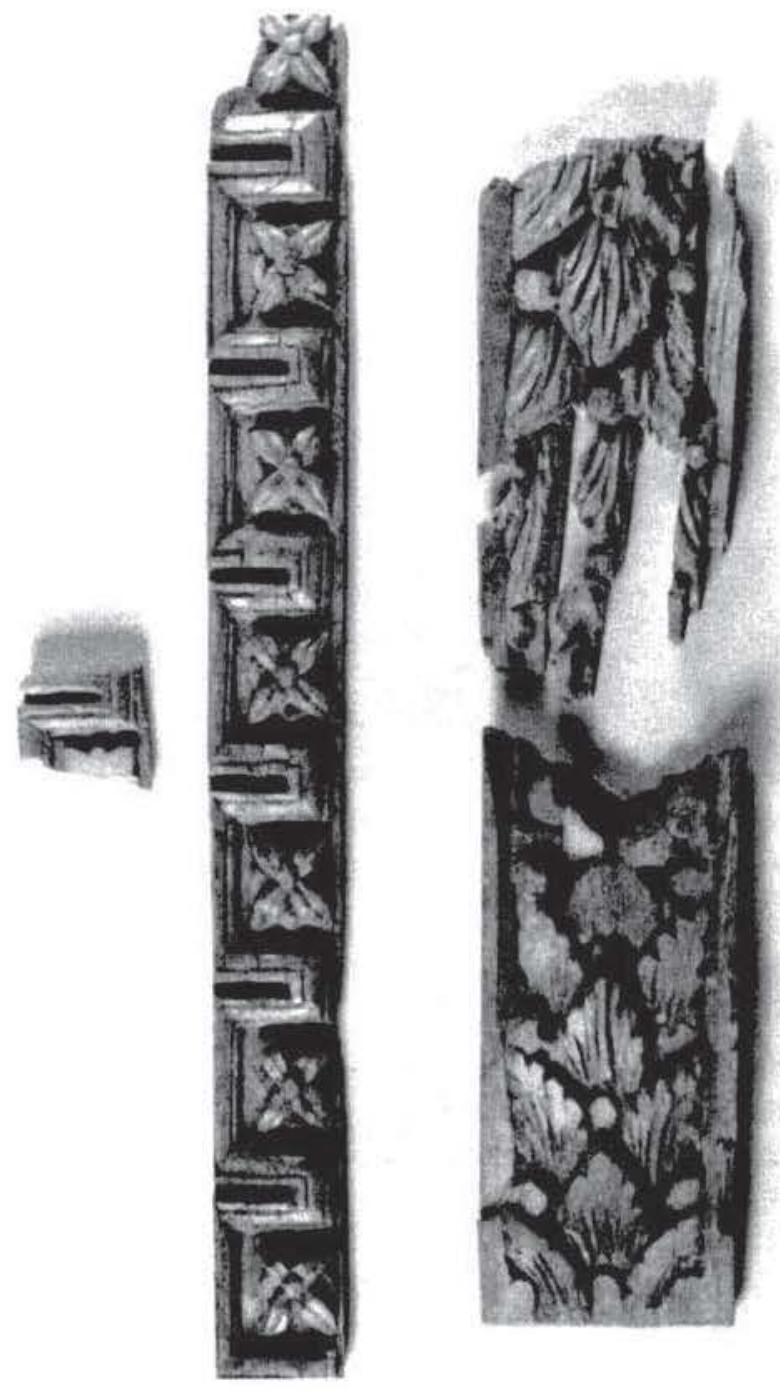

Figura 5. Placas con decoraciones de greca con florones y de roseta encuadrada por gurnaldas

arcos, con frisos superiores e inferiores, donde pudieron encuadrarse sendas figuras como la ninfa. En nuestra figura mostramos una reconstrucción hipotética y simplificada - sin los ábacos, y con una sola lamina en cada fuste de lo que pudo ser este tipo de decoración (fig. 6).

Ignoramos cómo pudieron ordenarse estos arcos: acaso en torno a un arcón; quién sabe si como obras yuxtapuestas, o bien como una gran tabla con una o dos tapaderas por delante, como la imagen conservada en una pieza de metal de Hadrumetum (Sousse $)^{10}$. Sea como fuere, es posible que el carácter casi cultual de la figura fuese la causa de su propia 11i. Véase en E. G. Budde, Armarium und Kibotós, Würzburg,
1939, fig. 28 y y 28 b. p. 38 .

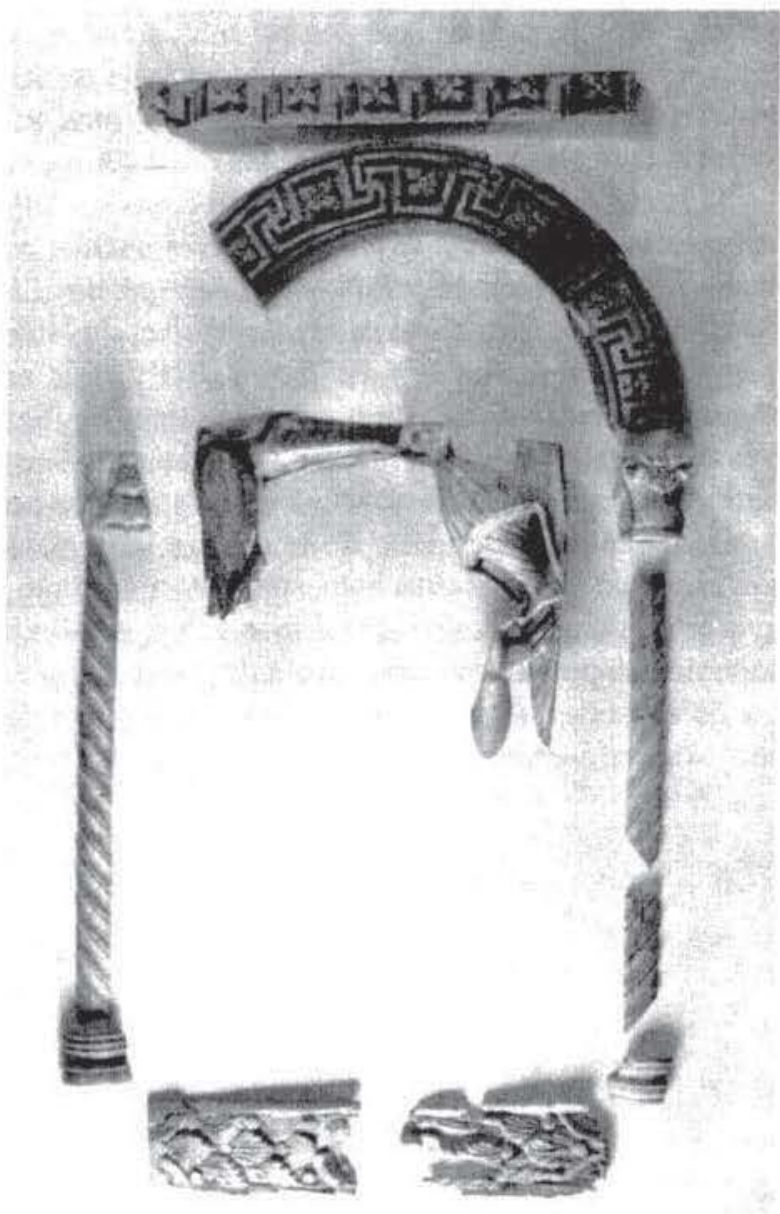

Figura 6. Reconstrucción hipotetica del panel decorativo de la ninfa.

destrueción en el momento de la crisis final del paganismo.

En cuanto al origen de esta decoración, de nuevo se impone el ambiente copto: los únicos paralelos de la greca de ménsulas con florones se hallan en ese mundo, sobre todo en talla de piedra o made$\mathrm{ra}^{11}$; lo mismo ocurre con las láminas de sección en arco de circulo para conformar fustes ${ }^{12}$; los mejores paralelos para los capiteles nos llevan en la misma dirección ${ }^{13}$, y a Egipto suelen atribuirse también las tallas de marfil más comparables con lo que

\footnotetext{
"Véase, por ejemplo J. Beckwith, op, cit. en nota9, figs 45 . 53. 71 y 124, o M. II. Rutchowscaya. op cit. en nota 4. n" $432,433,436,437,439$ y 441 .

L. Marangou, Bone Carvings from Egypt, Tübingen, 1976. lam. $64, n^{\circ} 265$.

${ }^{13} \mathrm{~L}$. Marangou, op. cit. en nota 12, p. 70, n"244 y 245.
} 
fue nuestra minfa'. Por tanto, podemas decir que. en fodos los casos donde domina un origen conereto para los demas elementos, los paratelos estan yeograficamente mas dicersificados la candidatura cgipeda se impone sur duda algunat el octogono de Valdetorres se mutrio, en arquetis 11 otro mobiliario menor. de la produccion de tan lejanos talleres. In cuanto a la cronologia. podemos afirmar. dentro de las incertidumbres yue siempre acompatian a este tipo de producctones. que una fecha en forno a lines del siglo 11 . o ya en el siglo 1 . seria aceptable para todas ellas. Son por tanto contemporáneas $\sin$ más de la edificación y corto periodo de vida del edificio que adomaron.

Solo una piesa una de las placas de fuste de columna - plantea, por su tosquedad de talla. una duda razonable: es posible que luese realizada ya en nuestra peninsula, para substituir otra placa parecida que se hubiese roto en el transporte. Is el unico elemento que haria suponer una produccion local. y el único punto de comparacion. en este sentido, que tendria quien quisiese abogar por el caracter hispano de la ultima pieza - y la más intrigantc de las halladas en Valdetorres.

Nos referimos al ya aludido "monstruo de Valdetorres" (fig 7). Se trata de una placa rota, deteriorada y quemada, que constituye una pieza única en nuestro contexto; sólo algún fragmento de placa lisa y quemada presenta su mismo tipo de marco en forma de linea de triangulos, sugiriendo la presencia de varios elementos adornando un mismo objeto; $y$. desde luego, el estilo de la tabla del amonstruom carece de cualquier relación con el resto de los marfiles

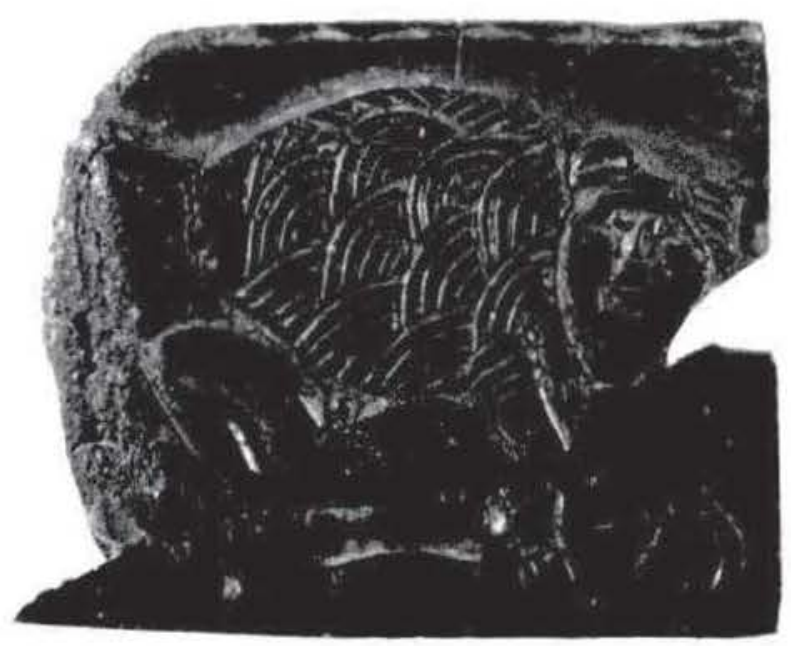

Figura 7. El emonstruo de Valdetorres"

"Es el caso de la Ariadna del Museo de Cluny y de las piezas de Aquisgran: véase bibliogratia en nuestra nota 9 . comcntados hasta ahora

Se trata de un relieve mus bajo. eon una eseena compuesta por dos planos bien determinados, y con una decoracion en la que predomina la labor de grabado y escasean las superfictes redondeadas. (on esta leenica, se nos representia un ser monstruoso

un gran cuerpo con la parte inferior perdida. cubetto con una decoración lineal de semeirculos cstructuradox como cecamas, y con una cabefa osal de aspecto humano. de la que stargen dos grandes orcjas. parecidas a las de un oso icon la pata que surge de su hombro y cuya garra o mano se ha perdido. el amensiruom apresa por el cuello una figura humana que se extiende bajo su vientre. EI hombre, tumbado sobre su espalda. muestra su pierna i/quierda la unica visible totalmente doblada. liene un punto para indicar sus genitales y. a causa de la destruccion por el fuego, resulta mal definible por lo demás: acaso cabria pensar que dobla el braso i/quierdo para apoyar su codo en el suelo. y que. Iras su perdida cabeza, surgiria una larga cabellera. casi como las hojas de una palmera convencional.

Por su estilo, la obra se enmarca de lleno dentro de esas tendencias, tan tipicas del Bajo Imperio y tan desarrolladas en las provincias extremas del mundo romano - Britannia, Hispania. Norte de Africa. Fgipto, Siria , que se caracterizan por una absoluta ruptura con la estetica clásica y por una busqueda expresiva muy directa e ingenua, que podriamos calilicar de popular ${ }^{19}$. En nuestra peninsula, sin duda el paralelo estilistico mas cereano to hallariamos en el conocido mosaico de Santisteban del Puerto (Jaén), con el tema de Aquiles en Scyros y la disputa de Marsias y Apolo 1", y bien sabido es que esta tendencia, con el tiempo, presidirá buena parte de la escultura en relieve visigoda - San Pedro de la Nave. Quintanilla de las Vinas, etc.- y merovingia estelas de Narbona, por ejemplo.

Por ello, seria muy importante saber situar el origen del «monstruo", fechable, como todo su contexto arqueológico, a fines del siglo iv o principios del v. En nuestra opinión. y a falta de datos en contra, debe prevalecer la lógica de la comunidad de origen de los marfiles de Valdetorres: si, salvo en un caso dudoso, todos proceden de Egipto, lo más correcto es pensar que éste viniese en el mismo lote de cofres y muebles, aunque el comerciante lo comprase a otro taller de carácter más popular, sin

Como aproximacion at este movimiento estetico. puede verse. por ejemplo, J. M* Blizque, a Iransformaciones sociales y descomposicion de las formas artisticas de la Antiguedad clásteam. Fragmentes. 10, 1987, p. 24-37, con la bibliografia que cita.

"Vease J. M". Bláqquez, Afosaicos romanes de Condoha. faén y. Malaga, Madrid, 1981, p. 66, n* 51. 
preocuparse por la diferencia de estilo. Como es bien sabido, en el mundo copto convivian tranquilamente los artesanos de carácter más culto y clasicista y los más anticlásicos, entre cuyos productos la estética de nuestro "monstruo" hallaria múltiples referencias. Además, y aunque se trate de un detalle menor, hemos de confesar que sólo en Egipto hemos hallado paralelos aunque más tardios y no idénticos- del marco en forma de serie de triángulos ${ }^{1}$.

Si, por su estilo, el «monstruo» nos habla ya más del futuro medievo que de la agonizante Antigüedad clásica, por su iconografía la situación no es muy diferente. Lo primero que nos sugieren sus extrañas formas es el mundo mozárabe de los Beatos, con sus temibles bestias apocalipticas. ¿Qué quiso mostrarnos el ingenuo creador de nuestra placa? El problema básico está en la pérdida del remate posterior del animal. Si este hubiese sido una cola de pájaro, por ejemplo, podria pensarse en una sirena deformada, devorando a una de sus victimas. Ignorante de la tradición iconográfica y textual de su época, el tallista la habría figurado sin manos y sin pechos, volviendo a una iconografia próxima a la del arcaísmo griego ${ }^{1 \times}$.

Pero hay un detalle compositivo que nos invita a buscar otra solución: el hecho de que la victima doble al máximo sus piernas hace pensar en la necesidad de lograr un espacio a la izquierda para colocar algo; y lo más probable es que ese algo fuesen las patas traseras del "monstruo», que sería asi un mamífero cuadrúpedo. Por lo demás, la trama de arcos de círculo que cubre el lomo sugiere más facilmente un pelo tupido que las plumas de una ave; como, por otra parte tal trama se corta hacia lo que sería la cintura del animal, cabe pensar que, en la mente del artista, se trataba de una fiera con melena leonina.

¿Quiso hacer un verdadero león, reflejando las últimas fiestas de anfiteatro, y le puso una cabeza humana por no saber representar la del felino? Sin negar la posibilidad, parece dificil que no hallase, en la profusa iconografia de los animales antiguos, un modelo utilizable. Y lo mismo diríamos si lo que

\footnotetext{
${ }^{17}$ M. H. Rutschowscaya, op. cit. en nota 4, p. $114-115, \mathrm{n}^{\circ} 372$ y 373 (obras del siglo viI).

${ }^{1 *}$ En realidad, esta vuelta atrás no seria única en las sirenas del arte popular de esta época: véase el caso de un mosaico de la provincia de Córdoba en J. M ${ }^{*}$. Blázquez, op. cit. en nota 16, p. $54, n^{\circ} 35$. Ese tipo de sirena tendrá gran proyección en el medievo: véase J. Mateo Gómez y A. Quiñones Costa, «Arpía o sirena: una interrogante en la iconografia románica», Fragmentos, 10,1987, p. $38-47$.
}

hubiese querido mostrarnos fuese una esfinge atacando a su victima; si. como pensamos, esta obra se hizo en Egipto, no debia el autor ignorar la iconografia de ese monstruo.

Como alternativa, solo se nos ocurre otra posibilidad, aunque ésta, por desgracia, carece de punto de apoyo iconográfico, y sólo lo tiene literario: nuestro autor pudo realizar la primera representación conocida de un monstruo ampliamente descrito por los naturalistas antiguos desde el siglo IV a.C. , y que tendrá gran fortuna en los bestiarios medievales: la marticora o manticora ${ }^{10}$. Se trataria de un animal que habitaba en la India. lo que coincidiria con la larga cabellera de su víctima, característica atribuida a los indios por los romanos ${ }^{20}$.

Esta fiera, cuyo nombre significa «comedor de hombres", tenia, según se nos dice, un cuerpo de león, cabeza humana y orejas casi humanas, aunque peludas. Evidentemente, se trata de una sugerencia hipotética, como todas las relativas a «primeras iconografias", pero no cabe olvidar que también fue en el siglo v, y en el sudeste del Mediterráneo, donde se crearon las primeras imágenes conocidas de otro monstruo destinado a tener larga vida: el unicornio 21 .

De cualquier modo, tanto el "monstruo» como el resto de nuestros marfiles permiten asentar una idea clara y documentada alli donde antes sólo cabian sugestivas hipótesis: por fin tenemos una base arqueológica para hablar de intercambios comerciales, allá por el 400 d.C., entre ambos extremos del Mediterráneo. $\mathrm{Y}$ de intercambios bastante intensos, pues, de lo contrario, mal podría explicarse la llegada de todo un lote de enseres con taracea de marfil a un lugar tan remoto y lejano de la costa como el valle del Jarama. Podrán, desde luego, discutirse las motivaciones del comprador a la hora de adquirir piezas de estilos diversos, pero, desde luego, siempre asombrará el hecho irrefutable de que, en el edificio de Valdetorres, llegó a reunirse uno de los conjuntos de marfiles mas ricos y refinados del occidente del Imperio, por más que la destrucción y el robo acabasen reduciéndolo a astillas.

\footnotetext{
${ }^{10}$ Este animal fue descrito por primera vez por Ctesias, quien dijo recibir noticias de su existencia durante su estancia en Persia: todos los autores antiguos se limitan a seguir su descripchón: Aristóteles, H. A., 2, 1, p. 501 a 24; Eliano, N. A., 4, 21 : Focio, Bibl., 72 p. 45 a $21-50$ a 4 , Pausanias, 9, 21, 4, (quien ya lo identifica como un tigre deformado por la fantasia); Plinio. N. H. 8, 75; Filostrato, V. Ap., III, 45 .

${ }^{20}$ Calistrato, 4 (Estatua de un indio), 1, habla de «cabellera tupida y abundante».

${ }^{21}$ M.A.Elvira, «Anotaciones sobre la iconografia del unicornio en Bizancio", Erytheia, 9.1, 1988, p. 143-165.
} 